Article

\title{
Pumping the Brakes on Robot Cars: Current Urban Traveler Willingness to Consider Driverless Vehicles
}

\author{
Scott B. Kelley ${ }^{1, *(\mathbb{C})}$, Bradley W. Lane ${ }^{2}$ and John M. DeCicco ${ }^{3}$ (1) \\ 1 Department of Geography, University of Nevada, Reno, Reno, NV 89557, USA \\ 2 School of Public Affairs and Administration, University of Kansas, Lawrence, KS 66045, USA \\ 3 University of Michigan Energy Institute, Ann Arbor, MI 48109, USA \\ * Correspondence: scottkelley@unr.edu; Tel.: +01-775-784-6705
}

Received: 26 August 2019; Accepted: 9 September 2019; Published: 15 September 2019

\begin{abstract}
A growing literature suggests that widespread travel conducted through driverless connected and automated vehicles (CAVs) accessed as a service, in contrast to those personally owned, could have significant impacts on the sustainability of urban transportation. However, it is unclear how the general public currently considers willingness to travel in driverless vehicles, and if they would be more comfortable doing so in one personally owned or one accessed as a service. To address this, we collected travel survey data by intercepting respondents on discretionary or social trips to four popular destinations in a medium-size U.S. city in the spring of 2017. After collecting data on how the respondent reached the survey site and the trip's origin and destination, survey administrators then asked if respondents would have been willing to make their current trip in either a personally-owned driverless vehicle or through a driverless vehicle service. Over one-third expressed willingness to use both forms, while $31 \%$ were unwilling to use either. For those that considered only one, slightly more favored the personally-owned model. Consideration of an existing mobility service was consistently a positive and significant predictor of those that expressed willingness to travel in a driverless vehicle, while traveling downtown negatively and significantly influenced consideration of at least one form of driverless vehicle. These findings highlight the diverse public views about the prospect of integration of CAVs in transportation systems and raise questions about the assumption that travelers to central city locations would be early adopters of automated vehicle mobility services.
\end{abstract}

Keywords: driverless vehicles; automated vehicles; connected vehicles; travel survey; logit model

\section{Introduction}

The development of driverless connected and automated vehicles (CAVs) could have transformative consequences for the transportation sector [1]. The effects remain speculative since CAV operation is still at an early experimental stage, and a great deal of technological and policy advancement will be required to facilitate their widespread use. Nevertheless, policymakers are actively considering how to integrate CAVs into existing urban transportation systems. Twenty-nine states have recently passed CAV-related legislation, and the governors of eleven states issued executive orders on the matter [2]. All of the major automobile manufacturers and many information technology (IT) companies are intensively developing CAVs, which also receive significant research and testing support from multiple levels of government. Thus, as vehicle technology continues to advance and public discussion continues about how to integrate CAVs into cities, there is a need to assess public willingness to consider the use of this potentially disruptive technology and how such adoption may influence urban planning and sustainability-related outcomes.

The growing literature on how CAV travel might affect environmental and social systems reflects the uncertainty about the willingness of the general public to travel using these vehicles [3,4]. Ongoing 
research on understanding the social and behavioral barriers to alternative fuel vehicle (AFV) adoption may offer some insights on potential initial CAV diffusion that is important to consider as CAV-related deployment plans develop. While many researchers have observed a high degree of variation at the individual level regarding willingness to consider AFV purchases [5-7], the most important attributes influencing uptake of these vehicles are those that provide personal benefits to the consumer-including low price, good fuel economy and driving performance, and cost-instead of environmental or societal benefits $[8,9]$. There is also significant variation in the public's knowledge of AFV technologies, their capabilities and supporting policies, as well as limited understanding of the effect of travel behavior on AFV adoption [10,11], which introduces some degree of uncertainty when considering diffusion and sustainability-related projections. Therefore, these findings on public adoption and consideration of AFVs may have some transferability to the question of future CAV adoption even as new barriers and uncertainties arise, but other considerations warrant attention.

One unique aspect of future CAV use that AFV adopters do not generally consider when making their decision to adopt the vehicle is the business model for vehicle ownership and operation, which is a primary source of uncertainty when projecting future sustainability-related impacts of CAVs, e.g., $[12,13]$. One option involves fleets of $C A V$ s owned by private entities such as a Transportation Network Company (TNC) or a public-private partnership. Under this model, customers would access CAVs as a service, similarly to that of present-day mobility-as-a-service (MaaS) systems, such as ride-hailing services like Uber or Lyft, or casharing services like ZipCar. We denote this approach as travel using a Service-provided (so-called "shared") driverless CAV (SCAV), in contrast to travel using a personally-owned ("private") driverless CAV (PCAV), which is similar to how individuals now procure and operate their own cars.

Indeed, there is growing interest in facilitating more widespread levels of future SCAV travel, and some analysts are optimistic that shifting travel to SCAVs would bring about a number of sustainability-related benefits under certain conditions [14,15]. However, the extent to which the public considers the prospect of using SCAVs, if at all, is quite unclear; yet more so is the degree to which the public is willing to transition away from the now-predominant means of travel using personally-owned vehicles [16]. It is therefore valuable to collect data on how consumers now view the prospects of future CAV travel, particularly as regional transportation planning agencies, automobile manufacturers, and private companies advance plans to integrate CAVs and their supporting infrastructure into cities.

In addition, limited attention has been devoted to understanding the spatial variation of prospective demand for CAV travel within cities and regions, and specifically, little data has been collected on CAV consideration by members of the public who are actively traveling to specific destinations within a city. This study fills these gaps by addressing the following research questions:

- To what extent do respondents agree or disagree that they would have completed their current trip, but with a car that drives itself, and how does such consideration vary for common travel destinations in a mid-sized US city?

- What is the nature of variation in stated willingness to specifically consider the use of a personally-owned driverless vehicle and a driverless vehicle service for respondents' current trips?

- What are the characteristics of respondents who express distinct willingness or unwillingness preferences for driverless vehicle travel by one or the other type of ownership model?

To address these questions, we conducted a travel intercept survey at popular destinations in Ann Arbor, Michigan, a medium-sized Midwestern town. Anchored by the University of Michigan, which has been involved in CAV research, development and testing for many years, Ann Arbor is beginning to consider the role that $\mathrm{CAV}$ s will have on its roadways in the future. This survey enabled us to characterize the nature of respondent willingness or unwillingness to consider prospective ways that PCAV or SCAV travel may work into distinct preference classifications. Descriptive analyses, cross-tabulations, and analysis of variance (ANOVA) tests were used to assess the nature of respondent characteristics by preference classification. Then, we estimated two sets of logit models to determine 
significant predictors of clear stated willingness or unwillingness to consider using a driverless vehicle for trips that the respondents were currently taking in the city.

\section{Overview of Relevant Literature}

Analyses of how CAVs might one day influence key transportation metrics-such as congestion, vehicle ownership, vehicle travel, criteria air pollution, greenhouse gas (GHG) emissions and energy consumption-indicate a wide range of potential impacts [12,13]. A primary source of uncertainty is whether CAVs would be personally owned and operated or accessed through a mobility service. A PCAV-dominated future, similarly to the present paradigm where individuals bear motor vehicle capital and operational costs, is unlikely to assuage the problems facing regional transportation systems. Indeed, a proliferation of PCAVs would likely continue to increase vehicle ownership levels [17] and facilitate future growth in total vehicle travel and energy demand [18-20].

In contrast, scenarios involving the widespread use of SCAVs instead of PCAVs project a number of benefits, such as a large reduction in the size of the total vehicle fleet [15]. However, there is less agreement that such a system would reduce overall vehicle travel, congestion and their impacts on energy demand, GHG emissions, criteria air pollution, and land use [21-25]. While uncertainties abound, it is unlikely that more promising benefits will be realized without widespread public acceptance of (1) CAVs as a desirable form of transportation, (2) CAV travel with vehicle ownership and operation transferred largely away from individuals to MaaS providers, and (3) high levels of trips with multi-rather than single-passenger occupancy [26].

Therefore, given the significant changes in current travel behavior that would be required to realize these benefits, researchers have begun to assess how willing people might be to use SCAVs. A study in the northeastern United States found that rail commuters considered SCAVs feasible for reaching train stations under certain density and congestion conditions [27]. Another modeled the interest in CAV usage in Austin, Texas, and found that $6.7 \%$ of current trips would be taken through SCAVs [23], while [14] found that, as for existing public transit modes, wait times and travel times are important for those considering the use of SCAVs. When considering factors that would make a transition to SCAVs more likely occur, [28] noted that dense, multi-modal urban areas may work well for such travel, but not lower density areas far from city centers. Studies that directly asked respondents about prospective $\mathrm{CAV}$ use have found that geographic and demographic characteristics influenced the willingness-to-pay (WTP) for certain CAV benefits $[29,30]$. While assessing WTP for services under various CAV scenarios offers useful insights, a high degree of uncertainty remains about how business models and pricing structures will evolve for either of the two types of CAV access considered here.

In contrast to stated preference surveys, some researchers have focused on how current usage of traditional and emerging mobility services can serve as an analog for future SCAV use and its ensuing outcomes [15]. For example, users of car sharing programs exhibit lower personal vehicle ownership rates and delay future vehicle purchases $[31,32]$ and the total vehicle miles travelled (VMT) of users relative to non-users also falls after a period of time [33]. While these findings are cause for some optimism, they come from studies of populations within select, relatively large and dense metropolitan areas with viable public transportation options in relatively walkable cities in North America, so the extent to which their findings can be generalized beyond those conditions is unclear. Indeed, participants in car-sharing programs are more likely to be regular users of public transit who did not have access to a vehicle [34], which is not reflective of the general population at present. Another recent study observed notable differences in travel behavior between car-sharing program participants in urban areas and suburban areas [35], implying that the service-based model may work well in certain areas but not in others.

Recent studies of TNC use also offer mixed perspectives on how widespread SCAV travel would affect sustainability-related outcomes in the transportation sector. While use of TNC services has expanded in recent years, it remains quite low relative to overall travel and is mostly concentrated 
in a few major urban areas [36]. Even in larger cities with relatively robust ride-hailing services and car-sharing programs, most residents have never used a ride-hailing service and even fewer have participated in car-sharing programs [37]. Those who use ride-hailing services are predominantly younger, male, higher-educated, and from a zero-car household, and they use the services primarily for social or recreational trips [38]. TNC users also frequently cite avoiding the need to find parking and avoiding the risk of driving while intoxicated as benefits of using such a service [36]. In addition to not being representative of the travel behavior of the general public, these findings suggest that the observed current use of travel modes that may emulate future SCAV use emphasizes social or recreational trips and travel in urban areas where driving a personal vehicle is more inconvenient. Thus, much remains to be studied about the diffusion of CAVs and their ownership models and their potential impact on cities, planning, and the sustainability of transportation.

\section{Methods}

Our research design utilized brief in-person intercept surveys conducted at two downtown and two suburban locations in a mid-size city in the midwestern United States. The survey asked respondents to consider their interest in replacing the trip they just made to the location with a vehicle that drove itself: either one they owned or accessed a service. Given the recent research on ride-hailing service use that identifies discretionary and social trips as the dominant user trip purpose [38], this study focuses on interviewing respondents at trip locations that capture these types of trips. For this study, then, commuting trips are not considered in this analysis, allowing the focus to be on the kinds of trips generally used by initial ride-hailing service users in urban areas at present. From the results, we identified four classifications of interest in CAVs. After conducting a series of ANOVA tests for key factors across classifications, we ran logit models with and without a location variable to predict the factors that influence someone to indicate that they definitely would or definitely would not take any form of a driverless vehicle for the intercepted trip.

\subsection{Study Area}

Ann Arbor is a mid-size city of approximately 122,000 people that anchors a designated Metropolitan Statistical Area (MSA) in Washtenaw County, Michigan, located at the western edge of the greater Detroit area in the southeastern part of the state. A relatively well-developed bus system operates within the cities of Ann Arbor and neighboring Ypsilanti, with select service to some smaller outlying towns. Both Uber and Lyft offer ride-hailing services in the city, as do a limited number of traditional taxi services. The car-sharing service ZipCar has a fleet of vehicles in Ann Arbor, primarily near the two University of Michigan campuses. Notably relevant for this survey population's relative knowledge regarding CAVs, the University of Michigan is a major research center for the technology, hosting the well-publicized Mcity test facility on its campus [39].

\subsection{Survey Locations}

An important aspect of this study was surveying travelers at a variety of destinations to collect information about driverless vehicle consideration by people actively conducting the kinds of trips that are now commonly taken by users of ride-hailing services. In contrast to traditional household travel surveys, and to recent web-based surveys about CAV perceptions and preferences, e.g., [29,30], this destination-specific approach did not ask respondents to consider driverless use for general purposes, but only for the specific trip that was in progress at the time of the interview.

Intercept surveys were conducted at the four sites within the city of Ann Arbor shown in Figure 1 during March and April 2017. Two were at downtown locations: one in the heart of the city's business district and the other at the Ann Arbor District Library (AADL) downtown facility. The other two sites were at outlying locations: Briarwood Mall, an enclosed shopping mall, and the Westgate shopping center's AADL site, located among a cluster of retail and service storefronts. Downtown Ann Arbor and the Briarwood Mall are frequented both by local residents and those from the surrounding region, 
and each offers a variety of amenities. The two library locations are visited largely by local residents, and these facilities act as community centers and gathering places that offer services and events to a wide range of the public.

The locations chosen enabled us to examine how public consideration of the CAV access options differed between respondents intercepted at sites that primarily facilitate automobile use compared to sites that also facilitate use of public transportation and other, non-motorized modes of travel. The Briarwood Mall and Westgate Library offer ample free parking and each is adjacent to an expressway at the edge of the city (Figure 1). Both also have some bus service. The two locations in Downtown Ann Arbor see relatively high volumes of pedestrian and bicyclist travel compared to the rest of the city, and free parking is not generally available except on Sundays. During the study period, parking rates ranged from $\$ 1.20$ per hour at the city garages to higher rates at on-street parking meters on all other days. The Downtown area hosts the city's popular restaurants, bars, and shops in a dense, walkable environment and is accessible by many of the city's bus routes.

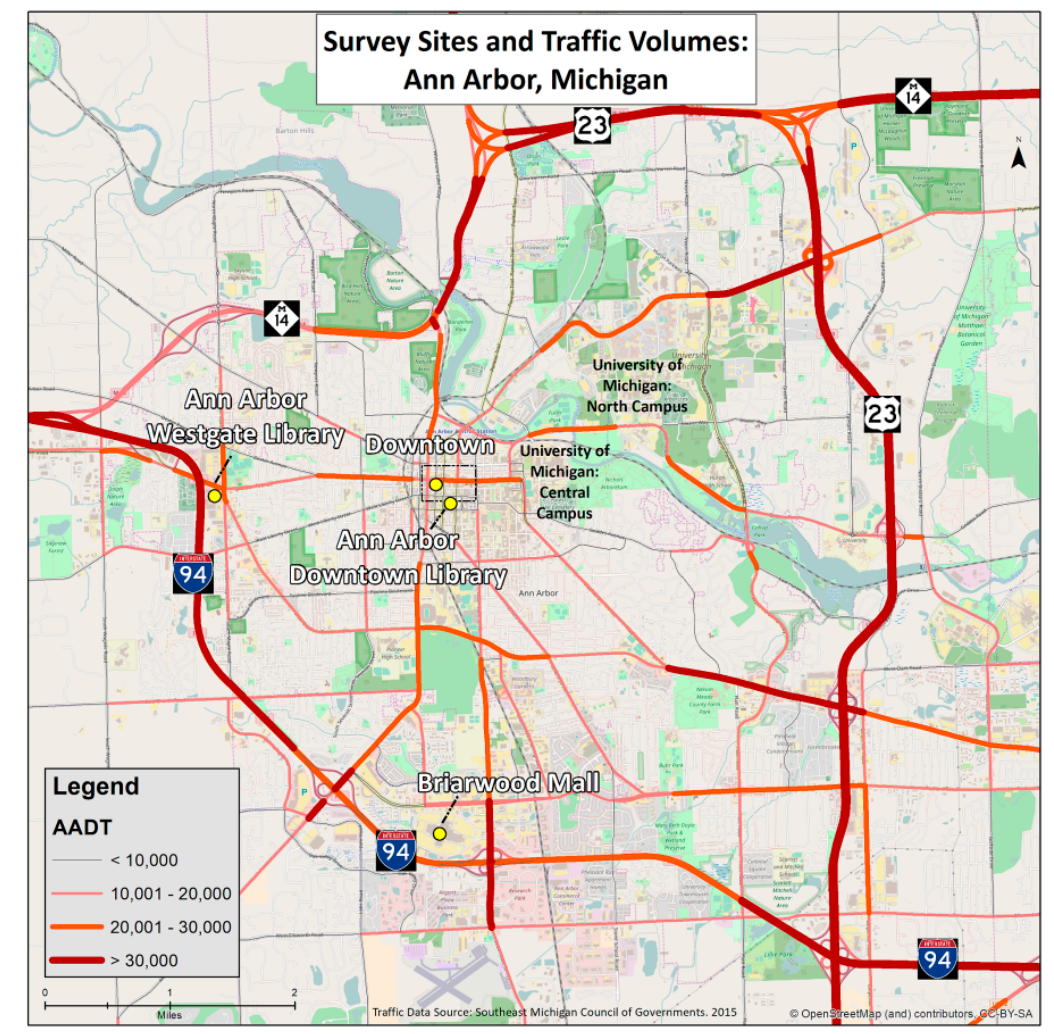

Figure 1. Study area and survey site locations in Ann Arbor, Michigan, with average annual daily traffic (AADT) volumes.

\subsection{Survey Instrument}

A set of teams, each comprised of two University of Michigan undergraduate students, administered the survey in person. The students stood near a kiosk or table (depending on the site) which included flyers that contained an overview of the study and contact information of the research team. At all locations except for along the streets of Downtown Ann Arbor, the students conducted the interviews next to a large poster that indicated that the survey was being conducted by researchers affiliated with the University of Michigan Energy Institute. Surveys were collected over a two-day period of time at each location. Each survey site included data collection both during one week day and on one weekend day.

Surveys were collected by verbally interviewing respondents and the student team recorded answers as respondents participated. The survey instrument and protocol received approval by the 
University of Michigan Institutional Review Board prior to dissemination. Pilot interviews were conducted before the formal survey period to refine the questions and gauge how to best approach respondents and clarify the topics and definitions of concepts. Given our focus on respondent willingness to consider the use of a vehicle that drove itself in either of the two ownership models of interest, we decided to use the term 'driverless vehicle' when interacting with survey respondents instead of using the terms 'connected vehicle', 'automated vehicle', or 'CAV'. The survey team asked all passing eligible respondents if they would be willing to participate in the study during the two-day survey period at each location. The response rate was approximately $20 \%$ and was relatively consistent across locations. In Downtown Ann Arbor, the teams of survey workers interviewed passing pedestrians along city sidewalks. At the two library locations and at Briarwood Mall, respondents were recruited and approached inside the establishment with permission from the establishment's owners. Respondents received a gift card to a local coffee shop as an incentive for participation. The survey instrument is available as a Supplementary Document included in this submission.

When a respondent agreed to participate, the student team began with a brief overview of the study's intent, then moved to a detailed verbal summary of driverless vehicle technology. To encourage respondents to imagine how they would travel in such a vehicle, we asked them to assume that the technology was fully operational and to focus on their degree of willingness to consider the idea of riding in a driverless vehicle. The team then gave verbal examples of the two driverless vehicle ownership model options. They told respondents that using a personally-owned driverless vehicle would be much like using a personal vehicle at present in that it would be one's own car, but that the car would drive itself. They then described using a driverless vehicle service-based model as similar to hailing a taxi cab or using a ride-hailing service, except that the car would drive itself. We did not specify the exact form of service-based ownership (TNC, city, public-private partnership, etc.), but stated that these were examples of entities that would operate the vehicles that the respondent would hail. While cost will unquestionably be a consideration for respondents in the future, given the high degree of uncertainty of this future landscape, we asked respondents not to consider that factor and instead focus solely on the idea of riding in a driverless vehicle, if it were available to them. For each interview, this introduction took 2-5 minutes; respondents were then given an opportunity to ask for clarification on the technology and two models in order to maximize the consistency of understanding among respondents.

After the overview, survey data collection began by confirming that the trip purpose was not commuting so that we could filter out respondents who may work at these locations. The first set of questions prompted respondents to state the mode of transportation that they used to reach the survey site, whether or not they considered the use of a shared mobility service for their current trip (if they did not use one to reach the destination), the approximate locations of the stops immediately before and after the survey site, and the respondent's approximate home location. These spatial data allowed us to identify where within greater Ann Arbor the respondent lived and to isolate the segment of the respondent's trip that included a stop at the survey site and their consideration of driverless vehicle travel. The second set of questions gathered information about household car ownership, total estimated time the respondent planned to spend at the survey site, and the respondent's age classification from a set of pre-defined categories. Next, we prompted respondents to recall the two general driverless vehicle access types, and express in a Likert-scale response (1-5) whether they strongly agreed, agreed, were neutral, disagreed, or strongly disagreed that they would have conducted this particular trip through a personally-owned driverless vehicle. We then asked the same question about willingness to consider making their current trip by a driverless vehicle service. We then provided an opportunity for respondents to express any other thoughts or concerns they had about driverless travel generally. In total, the surveys took nearly 10 minutes to complete, on average. 


\subsection{Geographic Data and Derived Metrics}

The respondents' home locations, given as either neighborhoods or approximate cross-streets instead of exact addresses, were stored as point feature data in a geographic information system (GIS). We then determined the percentage of all United States Census tracts within a quarter mile of a home location point that had a median income higher than the state of Michigan's 2015 overall median income, based on American Community Survey 2012-2016 five-year estimates. If all tracts exceeded this metric, we considered the respondent to live in a relatively wealthy area. This method also incorporated the spatial uncertainty of the approximate home locations. We also assessed whether the home location was within one-quarter mile of a bus stop as a proxy for the respondent's access to public transit. Distance between a home location and a transit stop was calculated by overlay analysis of service areas away from bus stops created using ArcGIS 10.5.1's Network Analyst instead of using Euclidean distance buffers. Bus stop locations were downloaded from the City of Ann Arbor's GIS data repository.

\section{Results}

Across the surveying dates, the student team collected 233 complete and usable intercept surveys from the four sites. Four additional potential respondents agreed to participate, but after indicating they worked at the location, they were not interviewed since these were commuting trips, and therefore not a discretionary or social trip to one of the survey sites. This small amount of intercepted commuters does indicate that commuting trips are relatively uncommon at these destinations. Response counts by intercept location are given in Table 1. Given the larger area and greater variety of travel purposes for respondents interviewed at the Downtown street site, we surveyed roughly twice as many individuals there as at the other three sites, which otherwise had similar respondent counts.

Table 1. Number of survey responses by location in Ann Arbor.

\begin{tabular}{cc}
\hline Location of Survey Site & Count \\
\hline Downtown streets & 92 \\
Downtown library & 48 \\
Westgate shopping center library & 52 \\
Briarwood Mall & 41 \\
\hline Total & 233 \\
\hline
\end{tabular}

\subsection{Driverless Vehicle Preference Willingness Groups}

Next, we categorized respondents' stated willingness to consider using personally-owned driverless vehicles and/or driverless vehicle services for their current trips. For simplicity, we combined the levels of response, grouping responses of "agree" and "strongly agree" together under "Agreement" and grouping "disagree" and "strongly disagree" together as "Disagreement". The category names were as follows:

- "Both": individuals who agreed that they would make the trip using a personally-owned driverless vehicle and also with a driverless vehicle service

- "Neither": individuals who disagreed that they would make the trip using a personally-owned driverless vehicle and also with a driverless vehicle service

- "Personal Only": individuals agreed that they would have made the trip using a personally-owned driverless vehicle but disagreed that they would have used a driverless vehicle service

- "As a Service Only": individuals agreed that they would have made the trip using a driverless vehicle service but disagreed that they would have used a personally-owned driverless vehicle

- "Neutral": neutral opinion to either question 
It is important to note that the terms 'PCAV' and 'SCAV' shown in Table 2 are for analytical purposes only: respondents were not introduced to these terms, and we use them in this section to signal how survey responses may align with these forms of future travel.

Table 2. Matrix of driverless vehicle preference groups.

\begin{tabular}{|c|c|c|c|c|}
\hline \multirow{2}{*}{\multicolumn{2}{|c|}{$\begin{array}{l}\text { Classifications and Response Percentages } \\
\text { (counts) }\end{array}$}} & \multicolumn{3}{|c|}{$\begin{array}{l}\text { Would Make the Trip Using a Personally Owned } \\
\text { Driverless Vehicle (PCAV) }\end{array}$} \\
\hline & & Agreement & Neutral & Disagreement \\
\hline \multirow{3}{*}{$\begin{array}{l}\text { Would make the trip using a } \\
\text { driverless vehicle service } \\
\text { (SCAV) }\end{array}$} & Agreement & $\begin{array}{c}\text { Both } \\
36 \%(84)\end{array}$ & $1 \%(2)$ & As a Service Only \\
\hline & Neutral & $1 \%(3)$ & $3 \%(7)$ & $<1 \%(1)$ \\
\hline & Disagreement & $\begin{array}{c}\text { Personal Only } \\
16 \%(36)\end{array}$ & $1 \%(2)$ & $\begin{array}{l}\text { Neither } \\
31 \%(73)\end{array}$ \\
\hline \multicolumn{2}{|c|}{$\begin{array}{l}\text { Number of usable responses: } \\
\qquad n=233\end{array}$} & \multicolumn{3}{|c|}{$\begin{array}{l}\text { "Agreement" sums "agree" and "strongly agree" responses } \\
\text { "Disagreement" sums "disagree" and "strongly disagree" } \\
\text { responses. }\end{array}$} \\
\hline
\end{tabular}

After categorizing responses for stated willingness to use a driverless vehicle for their current trip, 93\% of respondents gave a non-neutral answer to these questions, as shown in Table 2. Out of the 233 total respondents, just over one-third were "Both" respondents, while nearly one-third were "Neither" respondents, meaning that a majority of respondents indicated a consistent level of consideration of the two forms of driverless vehicles. Of those who agreed that they would have used one type of driverless vehicle but not both, PCAV interest appeared to be higher than that of SCAVs. Overall, a modest majority (63\%) said that they would have been willing to use at least one of the driverless vehicle types for their current trip. Nevertheless, with $31 \%$ of respondents falling into the "Neither" classification, a significant number of those surveyed seem to clearly express hesitation to use a driverless vehicle in order to make their current trip.

\subsection{Analysis of Variance and Post-Hoc Tests for Driverless Vehicle Preference Groups}

We then explored how these classification results might be explained by characteristics of the respondents and their intercepted trips by performing a series of one-factor ANOVA tests on the percentages of responses falling within the four driverless vehicle preference categories (excluding the neutral responses). Table 3 summarizes respondents' vehicle ownership levels, the modes of travel to the survey site, consideration of a shared mobility service, trip characteristics, along with respondents' age group and relative wealth of the area where they resided. Factors found to significantly differ include not owning a vehicle, considering the use of a shared mobility service to reach the site, driving alone to the survey site, walking or bicycling to the survey site, being younger than 35 , living near a bus stop, and residing in a relatively wealthy area.

In all categories, single vehicle ownership was most frequently observed. All the respondents classified as "Personal Only" stated that they owned at least one vehicle, in contrast to the other groups. For all except for those in the "Neither" group, most respondents reached the survey site by driving alone. Bus ridership levels were higher for those in the "Neither" and "As a Service Only" groups and differed significantly between all groups $(\alpha=0.10)$. "Personal Only" respondents reported home locations in wealthier areas with a lower proximity to bus stops compared to the respondents from other classifications. While there were notable differences in percentages of respondents under the age of 35 between groups, this was not the case for respondents over the age of 55, which, interestingly was highest for the "As a Service Only" group. No significant differences were observed in percentages of longer trips (greater than 10 miles), shorter trips (shorter than 3 miles), time spent at the survey site, or trip types relative to the home location (home-and-back, home-anchored, or non-home anchored trips).

A series of post-hoc Tukey tests isolated the individual group differences that produced the significant differences in Table 3. The paired-comparisons in Table 4 demonstrate that the primary 
differences were between: a) "Neither" and "Both" respondents, and b) "Neither" and "Personal Only" respondents. Lack of car ownership significantly differed between the "Personal Only" group and all other groups. There were significant differences between those driving alone and in use of walking or bicycling to reach the survey site between the "Neither" and "Personal Only" groups, but not between other pairs of groups. There were significant differences in the percentage of respondents under the age of 35 between the "Both" and "Neither" groups and between the "Both" and "Personal Only" groups, largely because of the high number of respondents under 35 in the "Both" group. Finally, the number of respondents who did not own a car was significantly lower in the "As a Service Only" group than in the "Personal Only" group, while "Personal Only" respondents lived in a wealthy area at higher rates than those in the "Both" and "Neither" groups.

Table 3. Characteristics by Driverless Vehicle Preference Groups and one-factor ANOVA test results.

\begin{tabular}{|c|c|c|c|c|c|c|c|c|c|c|}
\hline \multirow{2}{*}{$\begin{array}{c}\text { Variable } \\
\text { Vehicle Ownership }\end{array}$} & \multicolumn{2}{|c|}{$\begin{array}{c}\text { Both } \\
(n=84)\end{array}$} & \multicolumn{2}{|c|}{$\begin{array}{l}\text { Neither } \\
(n=73)\end{array}$} & \multicolumn{2}{|c|}{$\begin{array}{l}\text { Personal-Only } \\
\quad(n=36)\end{array}$} & \multicolumn{2}{|c|}{$\begin{array}{l}\text { Service Only } \\
\quad(n=25)\end{array}$} & \multicolumn{2}{|c|}{$\begin{array}{l}\text { TOTAL } \\
(n=233)\end{array}$} \\
\hline & $\%$ & SE & $\%$ & SE & $\%$ & SE & $\%$ & SE & $\%$ & SE \\
\hline Zero Vehicles ** & 26.5 & 4.9 & 30.1 & 5.4 & 0 & 0 & 32.0 & 9.5 & 24.0 & 2.8 \\
\hline One Vehicle & 44.6 & 5.5 & 42.5 & 5.8 & 55.6 & 8.4 & 36.0 & 9.8 & 43.8 & 3.3 \\
\hline Two or More & 28.9 & 5.0 & 27.4 & 5.3 & 44.4 & 8.4 & 32.0 & 9.5 & 32.2 & 3.1 \\
\hline Mode Used & $\%$ & SE & $\%$ & SE & $\%$ & SE & $\%$ & SE & $\%$ & SE \\
\hline Drove Alone $* *$ & 47.0 & 5.5 & 26.0 & 5.2 & 55.6 & 8.4 & 48.0 & 10.2 & 42.9 & 3.2 \\
\hline Multi-Occupant & 14.5 & 3.8 & 19.2 & 4.6 & 27.8 & 7.6 & 12.0 & 6.6 & 18.0 & 2.5 \\
\hline Bus $^{*}$ & 8.4 & 3.1 & 19.2 & 4.6 & 5.6 & 3.9 & 20.0 & 8.2 & 12.4 & 2.2 \\
\hline Walk or Bicycle ${ }^{* *}$ & 28.9 & 5.0 & 35.6 & 5.6 & 11.1 & 5.3 & 20.0 & 8.2 & 25.8 & 2.9 \\
\hline $\begin{array}{c}\text { Considered }{ }^{* *} \text { Using a Mobility } \\
\text { Service }\end{array}$ & 51.8 & 5.5 & 32.9 & 5.5 & 36.1 & 8.1 & 52.0 & 10.2 & 43.1 & 3.3 \\
\hline Trip Characteristics & $\%$ & SE & $\%$ & SE & $\%$ & SE & $\%$ & SE & $\%$ & SE \\
\hline After 4 pm & 34.9 & 5.3 & 20.5 & 4.8 & 25.0 & 7.3 & 28.0 & 9.2 & 27.0 & 2.9 \\
\hline Home and Back & 39.8 & 5.4 & 50.7 & 5.9 & 47.2 & 8.4 & 36.0 & 9.8 & 42.9 & 3.2 \\
\hline No Home Stop & 19.3 & 4.4 & 13.7 & 4.1 & 16.7 & 6.3 & 8.0 & 5.5 & 15.5 & 2.4 \\
\hline < 3 Miles & 38.6 & 5.4 & 46.6 & 5.9 & 25.0 & 7.3 & 40.0 & 10.0 & 38.6 & 3.2 \\
\hline$>10$ Miles & 22.9 & 4.6 & 21.9 & 4.9 & 36.1 & 8.1 & 28.0 & 9.2 & 26.2 & 2.9 \\
\hline$<1$ Hours & 39.8 & 5.4 & 26.0 & 5.2 & 36.1 & 8.1 & 24.0 & 8.7 & 33.0 & 3.1 \\
\hline$>4$ Hours & 16.9 & 4.1 & 23.3 & 5.0 & 13.9 & 5.8 & 28.0 & 9.2 & 20.2 & 2.6 \\
\hline Home is $>2.5$ Miles Away * & 47.0 & 5.5 & 39.7 & 5.8 & 66.7 & 8.0 & 48.0 & 10.2 & 49.1 & 3.3 \\
\hline Personal Characteristics & $\%$ & SE & $\%$ & SE & $\%$ & SE & $\%$ & SE & $\%$ & SE \\
\hline Under $35^{* *}$ & 56.6 & 5.5 & 35.6 & 5.6 & 19.4 & 6.7 & 36.0 & 9.8 & 40.8 & 3.2 \\
\hline Over 55 & 20.5 & 4.5 & 35.6 & 5.6 & 33.3 & 8.0 & 40.0 & 10.0 & 30.0 & 3.0 \\
\hline Home near Bus Stop * & 77.1 & 4.6 & 82.2 & 4.5 & 52.8 & 8.4 & 76.0 & 8.7 & 73.4 & 2.9 \\
\hline Lives in Wealthy Area* & 31.3 & 5.1 & 23.2 & 5.0 & 58.3 & 8.3 & 28.0 & 9.2 & 33.9 & 3.1 \\
\hline
\end{tabular}

For One-Way ANOVA tests, ${ }^{* *}$ significant $(\alpha=0.05),{ }^{*}$ significant $(\alpha=0.10)$.

Table 4. Post-hoc Tukey honest significant differences tests (adjusted $p$-values) for variables with at least one significant difference of means.






\subsection{Logit Modeling: Both and Neither Respondents}

Given the high frequency of respondents classified as either "Neither" or "Both", and the observed differences in key characteristics discussed in Section 4.2, we specified two different sets of logit models that isolated these responses. In the former case, we considered differences between the respondents who were willing to use at least one form of driverless vehicle travel relative to "Neither" respondents. Secondly, we considered differences between "Both" respondents relative to those who were unwilling to use at least one form of driverless vehicle travel. In each of these two modeling cases, we specified two separate models: one that included a dummy variable for whether or not the respondent was intercepted downtown and one that did not. This helped to compare the effect of downtown locations relative to suburban destinations between models. Independent variables were selected through a series of t-tests to identify metrics with significant differences between relevant groups, coupled with correlation matrices to mitigate the selection of multiple interdependent variables.

Table 5 demonstrates that driving alone to the survey site (odds ratio $(\mathrm{OR})=2.83$ ), conducting the trip after $4 \mathrm{pm}(\mathrm{OR}=1.98)$, having considered a mobility service for conducting the trip (OR =1.74), and being at a destination more than 2.5 miles from home $(\mathrm{OR}=1.67)$ were positive and significant predictors of willingness to consider a driverless vehicle of some form relative to "Neither" respondents. When adding the dummy variable that indicated whether or not the respondent was intercepted at a downtown site, being more than 2.5 miles from home was no longer a significant predictor, while a respondent being surveyed downtown became a negative and significant predictor $(\mathrm{OR}=0.56)$ of willingness to consider using at least one type of driverless vehicle to complete the trip. Driving alone, conducting the trip after $4 \mathrm{pm}$, and consideration of a mobility service for this trip remained positive and significant predictors when controlling for surveying a respondent in the downtown area.

Table 5. Logit model results: willingness to consider at least one form of driverless vehicle for current trip $\left(\mathrm{y}_{i}=1\right)$, versus unwillingness to consider either $\left(\mathrm{y}_{i}=0\right)$.

\begin{tabular}{|c|c|c|c|c|c|c|c|}
\hline \multicolumn{4}{|c|}{ At Least One vs. Neither: Basic } & \multicolumn{4}{|c|}{ At Least One vs. Neither: Survey Location } \\
\hline $\begin{array}{l}\text { Coefficients } \\
(\%)\end{array}$ & Est. & OR & $p$ & $\begin{array}{c}\text { Coefficients } \\
(\%)\end{array}$ & Est. & OR & $p$ \\
\hline Drove Alone & 1.04 & 2.84 & $<0.01 * *$ & Drove Alone & 0.81 & 2.25 & $0.02 * *$ \\
\hline Trip is After $4 \mathrm{pm}$ & 0.69 & 1.98 & $0.05^{* *}$ & Trip is After $4 \mathrm{pm}$ & 0.74 & 2.10 & $0.04 * *$ \\
\hline $\begin{array}{c}\text { Considered Mobility } \\
\text { Service }\end{array}$ & 0.55 & 1.74 & $0.07 *$ & $\begin{array}{c}\text { Considered Mobility } \\
\text { Service }\end{array}$ & 0.57 & 1.77 & $0.06^{*}$ \\
\hline $\begin{array}{l}\text { Distance to Home: } \\
>2.5 \text { miles }\end{array}$ & 0.51 & 1.67 & $0.09 *$ & $\begin{array}{l}\text { Distance to Home: } \\
>2.5 \text { miles }\end{array}$ & 0.45 & 1.56 & 0.14 \\
\hline Constant & 0.25 & 0.78 & 0.36 & $\begin{array}{c}\text { Surveyed Downtown } \\
\text { Constant }\end{array}$ & $\begin{array}{c}-0.59 \\
0.22\end{array}$ & $\begin{array}{l}0.56 \\
1.25\end{array}$ & $\begin{array}{c}0.09 * \\
0.57\end{array}$ \\
\hline \multicolumn{4}{|c|}{ Model Diagnostics } & \multicolumn{4}{|c|}{ Model Diagnostics } \\
\hline Log Likelihood & \multirow{2}{*}{\multicolumn{3}{|c|}{$\begin{array}{l}-133.3 \\
<0.01 * *\end{array}$}} & Log Likelihood & \multicolumn{3}{|c|}{-131.9} \\
\hline LR Test $(p)$ & \multirow{2}{*}{\multicolumn{3}{|c|}{$<0.01^{* *}$}} & LR Test $(p)$ & \multicolumn{3}{|c|}{$<0.01^{* *}$} \\
\hline AIC & \multicolumn{2}{|c|}{276.5} & & AIC & \multicolumn{3}{|c|}{275.7} \\
\hline Hosmer Lemeshow $(p)$ & \multicolumn{3}{|c|}{0.90} & Hosmer Lemeshow $(p)$ & \multicolumn{3}{|c|}{0.42} \\
\hline
\end{tabular}

Next, we specified logit models for "Both" respondents relative to those who expressed unwillingness to use at least one form of driverless vehicle. Table 6 demonstrates that a respondent being under the age of $35(\mathrm{OR}=2.88)$, staying less than an hour at the location $(\mathrm{OR}=2.01)$, and consideration of a mobility service for conducting their trip $(\mathrm{OR}=1.72)$, were positive and significant predictors of being a "Both" respondent. Adding the downtown survey site dummy variable to these models did not improve model fitness, and a respondent being surveyed downtown is not a significant predictor variable. The other three variables remained positive and significant predictors in the model that included the downtown variable, with slight differences introduced to the odds ratios. 
Table 6. Logit model results: willingness to consider both forms of driverless vehicle for current trip $\left(\mathrm{y}_{i}=1\right)$, versus unwillingness to consider at least one $\left(\mathrm{y}_{i}=0\right)$.

\begin{tabular}{|c|c|c|c|c|c|c|c|}
\hline \multicolumn{4}{|c|}{ Both vs. Otherwise: Basic } & \multicolumn{4}{|c|}{ Both vs. Otherwise: Survey Location } \\
\hline $\begin{array}{l}\text { Coefficients } \\
(\%)\end{array}$ & Est. & OR & $p$ & $\begin{array}{l}\text { Coefficients } \\
(\%)\end{array}$ & Est. & OR & $p$ \\
\hline Under 35 & 1.06 & 2.88 & $<0.01 * *$ & Under 35 & 1.04 & 2.82 & $<0.01 * *$ \\
\hline Stay $<1$ Hour at Location & 0.70 & 2.01 & $0.02 * *$ & Stay $<1$ Hour at Location & 0.74 & 2.10 & $0.02 * *$ \\
\hline $\begin{array}{l}\text { Considered Mobility } \\
\text { Service }\end{array}$ & 0.54 & 1.72 & 0.06 * & $\begin{array}{c}\text { Considered Mobility } \\
\text { Service }\end{array}$ & 0.55 & 1.74 & 0.06 * \\
\hline Constant & -1.54 & 0.21 & $<0.01 * *$ & $\begin{array}{l}\text { Surveyed Downtown } \\
\text { Constant }\end{array}$ & $\begin{array}{c}0.17 \\
-1.65\end{array}$ & $\begin{array}{l}1.19 \\
0.19\end{array}$ & $\begin{aligned} & 0.58 \\
< & 0.01 * *\end{aligned}$ \\
\hline \multicolumn{4}{|c|}{ Model Diagnostics } & \multicolumn{4}{|c|}{ Model Diagnostics } \\
\hline Log Likelihood & \multicolumn{3}{|c|}{-140.74} & Log Likelihood & \multicolumn{3}{|c|}{-140.59} \\
\hline LR Test $(p)$ & \multicolumn{3}{|c|}{$<0.01 * *$} & LR Test $(p)$ & \multicolumn{3}{|c|}{$<0.01 * *$} \\
\hline AIC & \multicolumn{3}{|c|}{289.49} & AIC & \multicolumn{3}{|c|}{291.17} \\
\hline Hosmer Lemeshow $(p)$ & \multicolumn{3}{|c|}{0.85} & Hosmer Lemeshow $(p)$ & \multicolumn{3}{|c|}{0.88} \\
\hline
\end{tabular}

Having considered a mobility service as an option for making the observed trip was consistently a positive and significant predictor in all four models. Driving alone, conducting the trip after $4 \mathrm{pm}$, and being interviewed relatively far from home significantly differed between those who indicated they would consider a driverless vehicle of either kind relative to "Neither" respondents, but these factors did not significantly differ between "Both" respondents and those who expressed unwillingness to use at least one form of driverless vehicle travel.

\section{Discussion}

When interviewing respondents who were actively traveling to popular destinations in Ann Arbor, Michigan for social or recreational purposes, we found notably high levels of both consistent stated willingness (36\%) and consistent stated unwillingness (31\%) to prospectively use a driverless vehicle for their trip. Fewer respondents expressed a preference for one ownership model over the other for their current trip and of those that did, the minority expressed a preference for a driverless vehicle service. This underscores the nature of the challenge in realizing a future in which SCAVs predominantly carry the burden of daily urban travel. The observed lack of relative interest likely underscores the hold that personal car ownership has in highly auto-dependent countries such as the United States. Moreover, the heterogeneity in stated willingness to consider driverless vehicle travel at present is relevant to discussions of introducing these vehicles into urban areas, and suggests that caution should be urged when projecting the widespread adoption and use of CAVs. As the technology continues to advance and its business models develop, the tendencies identified here may change, though to what degree and in which direction are uncertain. Nevertheless, our findings highlight the need to monitor the evolving public perceptions of these potential forms of future vehicle access.

The predictor that was consistently significant across the logit models was whether or not a respondent had considered an existing mobility service to complete their trip. This result parallels the findings seen on the effects of other disruptive transportation technologies. Factors such as knowledge of, exposure to, and prior experience with a hybrid or plug-in electric vehicle have consistently shown to be among the strongest factors influencing the further adoption of an AFV [11]. This should be of interest to future studies on driverless vehicle access, particularly those on future SCAV adoption, as it may be that a greater choice set size of transportation modes influences a respondent's willingness to consider other developing forms of transportation in general.

Traveling to a downtown location significantly influenced unwillingness to consider a driverless vehicle, but not for "Both" respondents. This is an important finding, given that downtown areas are often recommended as areas that would benefit from a transition to CAVs and are frequently highlighted as such in proposals that aim to introduce CAVs into urban areas [40]. Such recommendations often 
highlight the benefits of SCAVs in particular, which are claimed to help alleviate congestion and parking space requirements while providing additional accessibility for those living in multi-modal environments like that of downtown Ann Arbor. The finding that respondents surveyed in the city's downtown area were less willing to consider substituting their current trip for a driverless vehicle relative to those interviewed at the city's edge may reflect the characteristics of individuals who had chosen to reside in or visit an area where transit and active mobility allowed them to avoid needing an automobile specifically for non-work trips. Moreover, driving alone significantly influenced willingness to substitute a current trip with a driverless vehicle of some form. These results may suggest that the potential of CAVs to alleviate issues caused by vehicle travel in downtown areas may be overstated without policies closely aligned with that specific objective. Similarly, we found that those who lived in and traveled to automobile-friendly areas appeared to be more open to CAV use. Precisely how those who live in and travel to different urban environments contemplate future CAV use should be closely monitored as the technology continues to evolve.

There are several key uncertainties in this study that are important to consider as research in this area continues. One is the general state of public knowledge about driverless vehicle technology and ownership. In this research, while the student survey team provided a detailed overview of the technology and posed questions aimed at understanding initial public perceptions of driverless vehicle consideration, given the novelty of the technology and the lack of an operating vehicle or simulation to show to respondents, it is possible that some of those interviewed were not responding from a uniform baseline of familiarity with the concepts.

The relationship between general respondent travel behavior and willingness to consider the idea of travel by a driverless vehicle is also an area in which this study is limited. Here, we specifically considered how respondents would be willing to use a driverless vehicle for a particular trip that was discretionary or social in nature, making sure to include sites that attracted this trip purpose. We did not, however, ask respondents about how they would consider driverless vehicle use for all household travel purposes. It is possible that respondents in one of the four preference classifications would have responded differently to other trip types, including commuting. A traditional household survey approach that prompts respondents to consider a more comprehensive set of trip purposes may be helpful in understanding how different types of driverless vehicle ownership would be valuable in this regard. A wider range of destinations and a larger respondent sample size could provide more comprehensive information about how consumers may consider future CAV use. This could include scheduling more time at destinations or using web-based instruments in the future. Open-ended questions about why respondents preferred one, both, or neither of the vehicle types could also be used in future analysis to further understand traveler preferences for driverless vehicles.

The applicability of our results to other cities and regions is also uncertain. While this work makes novel contributions by utilizing a study site with a geographic and socio-economic profile different from the very large and dense metropolitan areas that are usually studied in this time of research, Ann Arbor nonetheless has unique and potentially non-generalizable characteristics. It is a relatively wealthy city, a major university anchors its economy and hosts a prominent research center for CAV technology, and its public transportation system is well developed by US standards. These factors likely influence how respondents currently travel as well as their attitudes and perceptions about transportation options. Since knowledge about CAVs may be higher in Ann Arbor than in most similarly sized cities, finding evidence of resistance to driverless vehicle use even in Ann Arbor suggests that the technology's diffusion rate may be slower than some projections indicate. Similar studies in different cities and regions will be necessary to determine how consistent the findings in this study are elsewhere. Additionally, seasonal travel differences may possibly have influenced the responses we received. In sum, many social, spatial, behavioral, and environmental factors will require further study before we understand the likely diffusion of CAVs and their implications for the transportation sector. 


\section{Conclusions}

This research establishes that there is significant variation and heterogeneity in respondent interest in considering travel in driverless vehicles at present for those on discretionary or social trips to popular travel destinations, regardless of whether such vehicle travel would occur in one personally-owned or accessed as a service. There appears to be a subset of the population for whom this form of travel is particularly appealing, another subset for whom it is particularly unappealing, and a third that indicates a preference for either privately-owned or shared access or expresses ambivalence. Despite significant popular and academic interest and belief in the rapid diffusion of autonomous vehicles and technology, this research indicates that much remains to be studied about consumer interest in adopting CAV technology, and that low public consideration of SCAVs at present remains a challenge that will need to be addressed should their introduction in future urban transportation systems continue to be proposed. Industry as well as policymakers would be wise to address this uncertainty prior to any rapid adoption of initiatives and incentives to integrate CAVs into the vehicle fleet.

Of policy relevance, our results suggest a need for caution about assuming that CAVs will be widely accepted in dense multi-use central areas of cities. At minimum, they confirm spatial variation in the present public willingness to consider driverless vehicle use, implying that greater attention should be devoted to understanding geographic and demographic variations in how these vehicles are perceived as a potential future form of urban transportation. The finding that one-third of respondents expressed clear unwillingness to consider either form of driverless vehicle travel indicates that greater attention should be devoted to understanding the circumstances of consumers when they do not view them as a desirable mode of urban transportation. Such research will be important for informing policymakers as they consider the potential role of CAVs to address the host of issues facing the transportation sector.

Supplementary Materials: The following are available online at http://www.mdpi.com/2071-1050/11/18/5042/s1, Survey Instrument.

Author Contributions: Conceptualization, S.K., B.L., and J.D.; Methodology, S.K., B.L., and J.D.; Software, S.K.; Validation, S.K., B.L., and J.D.; Formal Analysis, S.K., B.L.; Investigation, S.K., B.L., and J.D.; Resources, S.K. and J.D.; Data Curation, S.K. and J.D.; Writing-Original Draft Preparation, S.K., B.L., and J.D.; Writing-Review \& Editing, S.K., B.L., and J.D.; Visualization, S.K., B.L.; Supervision, J.D.; Project Administration, J.D.; Funding Acquisition, J.D.

Funding: The research reported here was supported in part by the U.S. Environmental Protection Agency (EPA), SPEED Program Grant No. 83594901, the University of Michigan Energy Institute (UMEI) and University of Michigan Dow Sustainability Fellows program

Acknowledgments: We would like to acknowledge the University of Michigan undergraduate student survey interview team of Jonathan Bain, Sheeba Pawar, and Sherelle Streeter for their efforts in collecting the surveys. We would also like to acknowledge Dr. Thomas Lyon at UMEI for his assistance with the survey design and feedback throughout the course of the study. Finally, we would like to acknowledge the staff at the Ann Arbor District Library, Briarwood Mall, and the city of Ann Arbor for their permission to conduct the survey at their locations and to Sweetwaters Coffee Shop for providing the incentives to survey respondents.

Conflicts of Interest: The authors declare no conflict of interest. The funders had no role in the design of the study; in the collection, analyses, or interpretation of data; in the writing of the manuscript, and in the decision to publish the results.

\section{References}

1. Mitchell, W.J.; Borroni-Bird, C.E.; Burns, L.D. Reinventing the Automobile: Personal Urban Mobility for the 21st Century; MIT Press: Cambridge, MA, USA, 2010.

2. National Conference of State Legislatures. Autonomous Vehicles: Self-driving Vehicles Enacted Legislation. Available online: http://www.ncsl.org/research/transportation/autonomous-vehicles-self-driving-vehiclesenacted-legislation.aspx. (accessed on 22 April 2019).

3. Papa, E.; Ferreira, A. Sustainable Accessibility and the Implementation of Automated Vehicles: Identifying Critical Decisions. Urban Sci. 2018, 2, 5. [CrossRef] 
4. Cohen, T.; Jones, P.; Cavoli, C. Social and Behavioural Questions Associated with Automated Vehicles; University College London Transport Institute Report: London, UK, 2017.

5. Hoen, A.; Koetse, M.J. A Choice Experiment on Alternative Fuel Vehicle Preferences of Private Car Owners in the Netherlands. Transp. Res. Part A 2014, 61, 199-215. [CrossRef]

6. Egbue, O.; Long, S.; Samaranayake, V.A. Mass Deployment of Sustainable Transportation: Evaluation of Factors That Influence Electric Vehicle Adoption. Clean Technol. Environ. Policy 2017, 19, 1927-1939. [CrossRef]

7. Axsen, J.; Kurani, K.S. Early U.S. Market for Plug-In Hybrid Electric Vehicles: Anticipating Consumer Recharge Potential and Design Priorities. Transp. Res. Rec. 2009, 2139, 64-72. [CrossRef]

8. Caulfield, B.; Farrell, S.; McMahon, B. Examining Individuals Preferences for Hybrid Electric and Alternatively Fueled Vehicles. Transp. Policy 2010, 17, 381-387. [CrossRef]

9. Lopez, O.; Stotts, R.; Kelley, S.B.; Kuby, M.J. Content Analysis of Early Adopters of Hydrogen Fuel Cell Vehicles in Los Angeles. Transp. Res. Rec. 2019, 74, 48-64.

10. Krause, R.M.; Lane, B.W.; Carley, S.; Graham, J.D. Assessing demand by urban consumers for plug-in electric vehicles under future cost and technological scenarios. Int. J. Sustain. Transp. 2016, 10, 742-751. [CrossRef]

11. Lane, B.W.; Carley, S.; Siddiki, S.; Dumortier, J.; Clark-Sutton, K.; Krause, R.M.; Graham, J.D. All plug-in electric vehicles are not the same: Predictors of preference for a plug-in hybrid versus a battery-electric vehicle. Transp. Res. Part D 2018, 65, 1-13. [CrossRef]

12. Brown, A.; Gonder, J.; Repac, B. An Analysis of Possible Energy Impacts of Automated Vehicles. In Road Vehicle Automation; Meyer, G., Beiker, S., Eds.; Springer: New York, NY, USA, 2014; pp. 137-153.

13. Wadud, Z.; MacKenzie, D.; Leiby, P. Help or hindrance? The travel, energy and carbon impacts of highly automated vehicles. Transp. Res. Part A 2016, 86, 1-18. [CrossRef]

14. Krueger, R.; Rashidi, T.H.; Rose, J.M. Preferences for Shared Autonomous Vehicles. Transp. Res. Part C 2016, 69, 343-355. [CrossRef]

15. Greenblatt, J.B.; Shaheen, S. Automated Vehicles, On-Demand Mobility, and Environmental Impacts. Curr. Sust./Renew. Energy Rep. 2015, 2, 74-81. [CrossRef]

16. United States Census Bureau. 2012-2016 American Community Survey 5-Year Estimates: Means of Transportation to Work. Available online: https:/factfinder.census.gov/faces/nav/jsf/pages/index.xhtml. (accessed on 1 July 2018).

17. Thomopoulos, N.; Givoni, M. The autonomous car-A blessing or a curse for the future of low carbon mobility? An exploration of likely vs. desirable outcomes. Eur. J. Futures Res. 2015, 3, 1-14. [CrossRef]

18. Auld, J.; Karbowskia, D.; Sokolova, V. Assessing the regional energy impact of connected vehicle deployment. In Proceedings of the World Conference on Transport Research, Shanghai, China, 10-15 July 2016.

19. Childress, S.; Nichols, B.; Charlton, B.; Coe, S. Using an activity-based model to explore possible impacts of automated vehicles. Transp. Res. Rec. 2015, 2493, 99-106. [CrossRef]

20. Gucwa, M. Mobility and energy impacts of automated cars. In Proceedings of the Automated Vehicles Symposium, San Francisco, CA, USA, 15-17 July 2014.

21. Levin, M.W.; Kockelman, K.M.; Boyles, S.D.; Li, T. A general framework for modeling shared autonomous vehicles with dynamic network-loading and dynamic ride-sharing application. Comput. Env. Urban Syst. 2017, 64, 373-383. [CrossRef]

22. Greenblatt, J.; Saxena, S. Autonomous taxis could greatly reduce greenhouse-gas emissions of US light-duty vehicles. Nat. Climate Change 2015, 5, 860-863. [CrossRef]

23. Zhang, W.; Guhathakurta, S.; Fang, J.; Zhang, G. Exploring the Impact of Shared Autonomous Vehicles on Urban Parking Demand: An Agent-Based Simulation Approach. Sust. Cities Soc. 2015, 19, 34-45. [CrossRef]

24. Fagnant, D.; Kockelman, K. The travel and environmental implications of shared autonomous vehicles, using agent-based model scenarios. Transp. Res. Part C 2014, 40, 1-13. [CrossRef]

25. Spieser, K.; Treleaven, K.; Zhang, R.; Frazzoli, E.; Morton, D.; Pavone, M. Toward a Systematic Approach to the Design and Evaluation of Automated Mobility-on-Demand Systems A Case Study in Singapore. In Road Vehicle Automation; Meyer, G., Beiker, S., Eds.; Springer: Bern, Switzerland, 2014; pp. 229-245.

26. Fulton, L.; Mason, J.; Meroux, D. Three Revolutions in Urban Transportation; University of California, Davis, Institute for Transportation Studies Research Report UCD-ITS-RR-17-03: Davis, CA, USA, 2017. 
27. Zachariah, J.; Gao, J.; Kornhauser, A.; Mufti, T. Uncongested Mobility for All: A Proposal for an Area Wide Autonomous Taxi System in New Jersey. In Proceedings of the 93rd Annual Meeting of the Transportation Research Board, Washington, DC, USA, 12-16 January 2014.

28. Litman, T. Autonomous Vehicle Implementation Predictions: Implications for Transport Planning; Report of the Victoria Transport Policy Institute: Victoria, BC, Canada, 2017.

29. Bansal, P.; Kockelman, K.M.; Singh, A. Assessing public opinions of and interest in new vehicle technologies: An Austin perspective. Transp. Res. Part C 2016, 67, 1-14. [CrossRef]

30. Kyriakidis, M.; Happee, R.; de Winter, J.C.F. Public opinion on automated driving: Results of an international questionnaire among 5000 respondents. Transp. Res. Part F 2014, 32, 127-140. [CrossRef]

31. Martin, E.W.; Shaheen, S. Greenhouse gas emission impacts of carsharing in North America. IEEE Trans. Intell. Transp. Syst. 2011, 12, 1074-1086. [CrossRef]

32. Lane, C. PhillyCarShare: First-year social and mobility impacts of carsharing in Philadelphia, Pennsylvania. Transp. Res. Rec. 2004, 1927, 158-166. [CrossRef]

33. Cervero, R.; Tsai, Y. City CarShare in San Francisco, California: second-year travel demand and car ownership impacts. Transp. Res. Rec. 2004, 1887, 117-127. [CrossRef]

34. Ballus-Armet, I.; Shaheen, S.; Clonts, K.; Weinzimmer, D. Peer-to-Peer Carsharing: Exploring Public Perception and Market Characteristics in the San Francisco Bay Area, California. Transp. Res. Rec. 2014, 2416, 27-36. [CrossRef]

35. Clewlow, R.R. Carsharing and Sustainable Travel Behavior: Results from the San Francisco Bay Area. Transp. Policy 2016, 51, 158-164. [CrossRef]

36. Clewlow, R.; Mishra, G.S. Disruptive Transportation: The Adoption, Utilization, and Impacts of Ride-Hailing in the United States; Institute for Transportation Studies Research Report UCD-ITS-RR-117-07: Davis, CA, USA, 2017.

37. Dias, F.F.; Lavieri, P.S.; Garikapati, V.M.; Astroza, S.; Pendyala, R.M.; Bhat, C.R. A Behavioral Choice Model of the Use of Car-Sharing and Ride-Sourcing Services. Transportation 2017, 44, 1307-1323. [CrossRef]

38. Rayle, L.; Dai, D.; Chan, N.; Cervero, R.; Shaheen, S. Just a better taxi? A survey-based comparison of taxis, transit, and ridesourcing services in San Francisco. Transp. Policy 2016, 45, 168-178. [CrossRef]

39. University of Michigan Transportation Research Institute. Mcity Grand Opening. UMTRI Res. Rev. 2015, 46, $1-3$.

40. Kelley, S.B.; Lane, B.W.; Stanley, B.W.; Kane, K.; Nielsen, E.; Strachan, S. Smart Transportation for All? A Typology of Recent U.S. Smart Transpiration Projects in Midsized Cities. Ann. Am. Assoc. Geogr. 2019, $1-12$.

(C) 2019 by the authors. Licensee MDPI, Basel, Switzerland. This article is an open access article distributed under the terms and conditions of the Creative Commons Attribution (CC BY) license (http://creativecommons.org/licenses/by/4.0/). 